\title{
The effects of aquatic walking and jogging program on physical function and fall efficacy in patients with degenerative lumbar spinal stenosis
}

\author{
Jae-Hyun Lee' ${ }^{1}$ Eunsook Sung ${ }^{2, *}$ \\ 'Department of Health and Fitness Management, College of Health and Welfare, Woosong University, Daejeon, Korea \\ ${ }^{2}$ Department of Sports Rehabilitation, College of Health and Welfare, Woosong University, Daejeon, Korea
}

The purpose of this study was to evaluate the effects of 12-week aqua walking and jogging program on muscle function, ankle range of motion (ROM), balance and fell efficacy in degenerative lumbar spinal stenosis (DLSS) patients. Six patients (2 males, 4 females) with DLSS participated in aquatic exercise program 3 times per week with each session of $60 \mathrm{~min}$ (warming-up, aqua walking, aqua jogging and cool down) at $1 \mathrm{~m}$ $20 \mathrm{~cm}-1 \mathrm{~m} 30 \mathrm{~cm}$ deep pool. Janda's muscle function test, ankle ROM, Berg balance scale (BBS) and fall efficacy scale (FES) were analyzed before and after the training intervention. We found significant increases in balance, muscle function, ankle ROM and fall efficacy after training intervention. In conclusion, aquatic exercise seems to affect physical function and fall efficacy positively in elderly DLSS patients.

Keywords: Lumbar spinal stenosis, Aqua exercise, Aqua jogging, Aqua walking

\section{INTRODUCTION}

As life expectancy increases, a larger number of patients suffer from lumbar spinal stenosis (LSS). The prevalence of lumbar spinal stenosis based on imaging criteria is estimated to be almost $50 \%$ in individuals older than age 60 (Boden et al., 1990; Kalichman et al., 2009). Degenerative lumbar stenosis (DLSS) shows bony overgrowth and ligament enlargement into the spinal canal (Yoshida et al., 1992) and diminished space available for the neural and vascular elements in the lumbar spine causes various symptoms (Kreiner et al., 2013). The symptoms include gluteal and lower extremity pain, numbness and motor weakness, which progressively get worsen by standing or walking and are alleviated by sitting (Genevay and Atlas, 2010; Kreiner et al., 2013). Therefore, LSS symptoms restrict walking capacity (Snyder et al., 2004) and increase the risk of falling (Kim et al., 2011).

Therapeutic exercises have shown to be effective in reduction of pain, improvement of disability, and increase of physical function among patients with chronic low back pain and LSS (Kim et al., 2014). Exercises for LSS patients often include unweighted walking or cycling, lumbar flexion exercises, hip mobility exercises and core strengthening (Backstrom et al., 2011; Iwamoto et al., 2010). However, to train with unweighted walking for LSS, particular machine is needed and it can be limitedly applied to LSS patients.

The upward thrust exerted by water on a body virtually eliminates the effects of gravity and the body's buoyancy reduces compression on the lower back, allowing for more pain free movement (Kaneda et al., 2007). Up to now, numerous studies have demonstrated that aquatic exercise has various advantages for elderly people. However, very few data exist on the physiological effect of aqua exercise on the DLSS patients. Therefore, we examined the effects of 12-week aqua walking and jogging program on muscle function, range of motion (ROM) of ankle, balance and fell efficacy in DLSS patients.
${ }^{*}$ Corresponding author: Eunsook Sung

Department of Sports Rehabilitation, College of Health and Welfare, Woosong

University, 171 Dongdaejeon-ro, Dong-gu, Daejeon 34606, Korea

Tel: +82-42-630-9844, Fax: +82-42-630-9215, E-mail: ses975@wsu.ac.kr

Received: August 19, 2015 / Accepted: October 1, 2015
This is an Open Access article distributed under the terms of the Creative Commons Attribution Non-Commercial License (http://creativecommons.org/licenses/by-nc/3.0/) which permits unrestricted non-commercial use, distribution, and reproduction in any medium, provided the original work is properly cited. 


\section{MATERIALS AND METHODS}

\section{Subjects}

6 subjects ( 2 males, 4 females) with DLSS participated in the study (Table 1). They had previously been screened and diagnosed by an orthopedic surgeon. They had not been getting active treatments; none of them had surgery before and were currently not performing training. The subjects didn't present any neurological signs of pathological importance in the clinical examination. Prior to the study, participants were informed about the purpose, procedures and risks of the study and written informed consent was obtained from each participant.

\section{Aquatic exercise program}

Subjects participated in aquatic exercise program 3 times per week with each session of $60 \mathrm{~min}$ at $1 \mathrm{~m} 20 \mathrm{~cm}-1 \mathrm{~m} 30 \mathrm{~cm}$ deep pool. The program was composed of warming-up (10 min), aqua walking (20 min), aqua jogging (20 min), and cool down (10 $\min )$.

\section{Janda's muscle function test}

Janda's muscle function test was developed (Janda, 1983) for muscles responsible for movement in the face, trunk, upper limb

Table 1. Physical characteristics of subjects

\begin{tabular}{|c|c|c|c|c|c|c|}
\hline & Subject 1 & Subject 2 & Subject 3 & Subject 4 & Subject 5 & Subject 6 \\
\hline $\operatorname{Sex}(M / F)$ & $M$ & $M$ & $\mathrm{~F}$ & $\mathrm{~F}$ & $\mathrm{~F}$ & $\mathrm{~F}$ \\
\hline Age (yr) & 65 & 67 & 66.8 & 60 & 71 & 74 \\
\hline Height (cm) & 165 & 183 & 162 & 153 & 156 & 157 \\
\hline Weight (kg) & 53.6 & 69.3 & 75 & 57.4 & 60.4 & 65.2 \\
\hline
\end{tabular}

M, Male; F, female. and lower limb. Through this test, shortened muscles for limited joint movements and hypermobile joints can be identified. At the start of each subsection, the relevant joint movements, muscle and nerve supply were explained and proper test position was demonstrated to the subjects. In each test, muscle function was assessed with regard to a 6 point scale, which ranges between normal function (score 0 ) and complete shortness or contracture (score 6).

\section{ROM of ankle}

Subjects lay supine with outstretched legs on an examination table without any pad, cushion or pillow underneath. The testing position of ankle started $90^{\circ}$ and the ROM of the ankle was calculated by the summation of degrees of plantar flexion and dorsi flexion. The greater degree means the higher flexibility.

\section{Berg balance scale (BBS)}

The BBS was developed (Jogi et al., 2011) as a performance-oriented measure of balance in elderly individuals. The BBS consists of 14 items that are scored on a scale of 0 to 4 . A score of 0 is given if the participant is unable to do the task, and a score of 4 is given if the participant is able to complete the task based on the criterion that has been assigned to it. The maximum total score on the test is 56.

\section{Fall efficacy scale (FES)}

FES was developed by Azad et al. (2014) and is a questionnaire composed of 16 items of simple mobility tasks and more difficult tasks including the 10 original items and six new items assessing walking on slippery, uneven or sloping surfaces, and visiting friends or relatives, going to a social event or going to a place with crowds. We used the revised FES instructions and response categories that

Table 2. The change of score of muscle function test and ankle ROM

\begin{tabular}{|c|c|c|c|c|c|}
\hline Test item & & Pre & Post & $t$ & $P$ \\
\hline \multirow[t]{9}{*}{ Janda's muscle function test } & Gastrocnemius & $1.8 \pm 0.7$ & $0.5 \pm 0.5$ & 8 & $0.000^{*}$ \\
\hline & Soleus & $1.7 \pm 0.8$ & $0.5 \pm 0.5$ & 7 & $0.001^{*}$ \\
\hline & Ilipsoas & $1.6 \pm 0.8$ & $0.3 \pm 0.4$ & 5.394 & $0.003^{*}$ \\
\hline & Rectus femoris & $1.2 \pm 0.4$ & $0.1 \pm 0.2$ & 5.398 & $0.003^{*}$ \\
\hline & Hamstring & $1.4 \pm 0.4$ & $0.3 \pm 0.4$ & 4.719 & $0.005^{*}$ \\
\hline & Pectoralis & $0.3 \pm 0.6$ & $0.3 \pm 0.4$ & 1 & 0.363 \\
\hline & Abductor muscles of thigh & $0.2 \pm 0.4$ & $0.1 \pm 0.2$ & 0.415 & 0.695 \\
\hline & Neck muscles & $0.9 \pm 0.8$ & $0.5 \pm 0.5$ & 2.076 & 0.093 \\
\hline & Back muscles & $1.0 \pm 0.0$ & $0.3 \pm 0.3$ & 6.708 & $0.001^{*}$ \\
\hline Ankle ROM & & $53.8 \pm 11.8$ & $68.8 \pm 8.6$ & -7.006 & $0.001^{*}$ \\
\hline
\end{tabular}

${ }^{*} P<0.05$.

ROM, Range of motion. 
Table 3. The change of BBS and FES

\begin{tabular}{llccc} 
& Pre & Post & $t$ & $P$ \\
\hline BBS & $27.2 \pm 4.9$ & $34.7 \pm 3.3$ & -4.728 & $0.005^{*}$ \\
FES & $73.0 \pm 21.4$ & $98.8 \pm 2.4$ & -3.022 & $0.029^{*}$ \\
\hline
\end{tabular}

${ }^{*} P<0.05$.

BBS, Berg balance scale; FES, fall efficacy scale.

assess level of concern about falling when carrying out each activity on a four point scale ( $1=$ not at all concerned, $4=$ very concerned).

\section{Statistical analysis}

Data are presented as mean values with SD. A paired t-test was used to evaluate differences between before and after training. SPSS software (SPSS for Windows, version 22.0, Chicago, IL, USA) was used for all analyses, and a $P$-value of 0.05 was set for significance.

\section{RESULTS}

\section{Muscle function and ankle flexibility}

The scores of Janda's muscle function tests were significantly decreased after exercise program in back muscle and lower body muscles except abductor of thigh. however, pectoralis major and neck muscle didn't show any change between pre and post exercise. Ankle $\mathrm{ROM}$ was also significantly increased from $53.8 \pm 11.8^{\circ}$ to $68.8 \pm 8.6^{\circ}$ (Table 2 ).

\section{Fall efficacy and balance}

After 12 week program, the scores of BBS and FES were significantly increased from $27.2 \pm 4.9$ to $34.7 \pm 3.3$ and $73.0 \pm 21.4$ to $98.8 \pm 2.4$, respectively. It means that aquatic exercise program affected the function of balance and confidence of not falling positively in the patients with stenosis (Table 3).

\section{DISCUSSION}

DLSS can cause decreased strength, balance and impaired gait pattern (ECRI Health Technology Assessment Group, 2001) and overall stiffness (Backstrom, 2011). One of the common symptoms of LSS is neurogenic claudication which progressively get worsen by standing or walking and are alleviated by sitting (Genevay and Atlas, 2010; Kreiner et al., 2013). Therefore, Individuals with LSS commonly show the reduced walking tolerance (Onel et al., 1993) and have a risk of a fall comparable with the patients of degenerative knee osteoarthritis (Kim et al., 2011).
To decrease the risk of falling by improving physical function in DLSS patients, aquatic walking and jogging program was executed in our study. Water supplied safe environment to the patients having ambulation problem and permitted them upright exercise. As a result, 12 week aquatic exercise showed positive effects such as increases of balance, muscle function, ankle ROM and fall efficacy in elderly DLSS patients. Many other studies have demonstrated that water exercise is effective in increasing muscle strength, flexibility, balance and fall efficacy in elderly people (Fisken et al., 2015; Kim and O'Sullivan, 2013; Sato et al., 2011). The combined properties of hydrostatic pressure and viscosity of water provide favorable conditions for resistance and proprioceptive training. These features of water might have acted positively to improve balance, muscle function and flexibility. And another reason for improvement of physical function is exercise itself. The buoyancy of water can relieve the limitation of the movement by pain and fear of falling of LSS patients. It permitted them relatively active movements. The improvements of balance, muscle function and ankle ROM might have affected the increase of fall efficacy positively because balance deficit and muscle weakness are main risk factors for falling (Rubenstein, 2006; Rubenstein and Josephson, 2006) and ankle is the important body part for the strategy of keeping balance and avoiding falling (Winter, 1995).

In the absence of a control group, we can only surmise that the results in our study were probably a combination of the effect of intervention and the natural course of DLSS. Further researches are needed to verify current results and draw conclusions regarding independent effectiveness of aquatic exercise as a treatment for DLSS.

\section{CONFLICT OF INTEREST}

No potential conflict of interest relevant to this article was reported.

\section{REFERENCES}

Azad A, Hassani Mehraban A, Mehrpour M, Mohammadi B. Clinical assessment of fear of falling after stroke: validity, reliability and responsiveness of the Persian version of the Fall Efficacy Scale-International. Med J Islam Repub Iran 2014;28:131.

Backstrom KM, Whitman JM, Flynn TW. Lumbar spinal stenosis-diagnosis and management of the aging spine. Man Ther 2011;16:308-317.

Boden SD, Davis DO, Dina TS, Patronas NJ, Wiesel SW. Abnormal magnetic-resonance scans of the lumbar spine in asymptomatic subjects. A 
prospective investigation. J Bone Joint Surg Am 1990;72:403-408.

Fisken AL, Waters DL, Hing WA, Steele M, Keogh JW. Comparative effects of 2 aqua exercise programs on physical function, balance, and perceived quality of life in older adults with osteoarthritis. J Geriatr Phys Ther 2015;38:17-27.

Genevay S, Atlas SJ. Lumbar spinal stenosis. Best Pract Res Clin Rheumatol. 2010;24:253-265.

Goren A, Yildiz N, Topuz O, Findikoglu G, Ardic F. Efficacy of exercise and ultrasound in patients with lumbar spinal stenosis: a prospective randomized controlled trial. Clin Rehabil 2010;24:623-631.

Iwamoto J, Sato Y, Takeda T, Matsumoto H. Effectiveness of exercise in the treatment of lumbar spinal stenosis, knee osteoarthritis, and osteoporosis. Aging Clin Exp Res 2010;22:116-122.

Janda V. On the concept of postural muscles and posture in man. Aust J Physiother 1983;29:83-84.

Jogi P, Spaulding SJ, Zecevic AA, Overend TJ, Kramer JF. Comparison of the original and reduced versions of the Berg Balance Scale and the Western Ontario and McMaster Universities Osteoarthritis Index in patients following hip or knee arthroplasty. Physiother Can 2011;63:107114.

Kalichman L, Cole R, Kim DH, Li L, Suri P, Guermazi A, Hunter DJ. Spinal stenosis prevalence and association with symptoms: the Framingham Study. Spine J 2009;9:545-550.

Kaneda K, Wakabayashi H, Sato D, Nomura T. Lower extremity muscle activity during different types and speeds of underwater movement. J Physiol Anthropol 2007;26:197-200.

Kim ER, Kang MH, Kim YG, Oh JS. Effects of a home exercise program on the self-report disability index and gait parameters in patients with lumbar spinal stenosis. J Phys Ther Sci 2014;26:305-307.

Kim HJ, Chun HJ, Han CD, Moon SH, Kang KT, Kim HS, Park JO, Moon ES, Kim BR, Sohn JS, Shin SY, Jang JW, Lee KI, Lee HM. The risk as- sessment of a fall in patients with lumbar spinal stenosis. Spine (Phila Pa 1976) 2011;36:E588-E592.

Kim SB, O'sullivan DM. Effects of Aqua Aerobic Therapy Exercise for Older Adults on Muscular Strength, Agility and Balance to Prevent Falling during Gait. J Phys Ther Sci 2013;25:923-927.

Kreiner DS, Shaffer WO, Baisden JL, Gilbert TJ, Summers JT, Toton JF, Hwang SW, Mendel RC, Reitman CA; North American Spine Society. An evidence-based clinical guideline for the diagnosis and treatment of degenerative lumbar spinal stenosis (update). Spine J 2013;13:734743.

Onel D, Sari H, Dönmez C. Lumbar spinal stenosis: clinical/radiologic therapeutic evaluation in 145 patients. Conservative treatment or surgical intervention? Spine (Phila Pa 1976) 1993;18:291-298.

Rubenstein LZ, Josephson KR. Falls and their prevention in elderly people: what does the evidence show? Med Clin North Am 2006;90:807824.

Rubenstein LZ. Falls in older people: epidemiology, risk factors and strategies for prevention. Age Ageing 2006;35 Suppl 2:ii37-ii41.

Sato D, Kaneda K, Wakabayashi H, Shimoyama Y, Baba Y, Nomura T. Comparison of once and twice weekly water exercise on various bodily functions in community-dwelling frail elderly requiring nursing care. Arch Gerontol Geriatr 2011;52:331-335.

Snyder DL, Doggett D, Turkelson C. Treatment of degenerative lumbar spinal stenosis. Am Fam Physician 2004;70:517-520.

Winter D. Human balance and posture control during standing and walking. Gait Posture 1995;3:193-214.

Yoshida M, Shima K, Taniguchi Y, Tamaki T, Tanaka T. Hypertrophied ligamentum flavum in lumbar spinal canal stenosis. Pathogenesis and morphologic and immunohistochemical observation. Spine (Phila Pa 1976) 1992;17:1353-1360. 